\title{
E्दुreatidaro
}

\section{A Educação na Prisão não é uma Mera Atividade}

Marc De Maeyer

RESUMO - A Educação na Prisão não é uma Mera Atividade. A educação e a prisão sempre formaram um par incoerente: a primeira encontrando sua justificação universal no contexto particular da segunda que, no entanto, por natureza, oferece apenas um quadro contraditório para a livre expressão da primeira. Como a prisão, que é antieducativa em si, pode oferecer às pessoas, uma possibilidade de contar com aprendizados úteis no seu momento presente e que lhe servirão até a sua saída? O artigo tentará mostrar que, em meio a essas contradições, uma educação é possível com a condição de que esta última seja efetivamente uma educação para toda a vida e não o ensino ou a reeducação.

Palavras-chave: Educação e Prisão. Educação para toda a Vida. Bibliotecas na Prisão.

ABSTRACT - Education in Prison is not Only an Activity. Education and prison have always formed an incoherent pair: the first, finding its universal reasons in the particular context of the second, which, by its nature, offers only a contradictory frame for the free expression of the first one. How can prison, being anti-educative by itself, offer people an opportunity to explore useful knowledge from now until the day they are released? We will try to demonstrate that, amidst these contradictions, education is possible with the proviso that it is effectively an education for life, and not only instruction or reeducation.

Keywords: Education and Prison. Education for Life. Libraries in Prison. 
A Educação na Prisão não é uma Mera Atividade

A educação e a prisão sempre formaram um par incoerente: a primeira encontrando sua justificação universal no contexto particular da segunda que, no entanto, por natureza, oferece apenas um quadro contraditório para a livre expressão da primeira.

Como a prisão, que é antieducativa em si, pode oferecer às pessoas que não pediram para estar lá e que só raramente reivindicam programas educacionais, uma possibilidade de contar com aprendizados úteis no seu momento presente e que lhe servirão até a sua saída? A menos que se considere, como alguns, que repressão e educação são as duas faces da mesma moeda.

Nessas poucas páginas, tentaremos mostrar que, em meio a essas contradições, uma educação é possível com a condição de que esta última seja efetivamente uma educação para toda a vida e não o ensino ou a reeducação. Diremos também que, mesmo trabalhando nessas contradições, os educadores e os educandos devem poder se beneficiar de condições essenciais à circulação das ideias, mesmo que os corpos não possam circular livremente.

Veremos, enfim, através do exemplo das bibliotecas que, na prisão, nenhuma iniciativa educacional (ou social) terá impacto significativo sem a participação dos principais interessados. Os educadores, que nos honram com sua leitura, sabem também que essa não é apenas uma questão concernente à prisão.

\section{Quando a Prisão Cria uma Demanda por Educação que, no entanto, não Pode Atender}

A demanda por educação na prisão é paradoxal: ela vem frequentemente da administração que tendo, sem dúvida, medo do ócio, realiza atividades que permitirão aos detentos suportar o menos mal possível a perda de sua liberdade. Competições esportivas e recreativas, a religião, possibilidades de trabalho em oficinas, formações profissionais e cursos às vezes são oferecidos aos detentos - isso depende dos países e dos continentes. Além do bem estar físico, social e intelectual que essas inciativas devem trazer, elas são destinadas, sobretudo, a manter a calma no interior da instituição. A natureza (humana) aterrorizada pelo ócio.

A educação, sem muitas indicações sobre seu conteúdo e seu dinamismo, se vê então no centro das preocupações da instituição. Como se um futuro educando fosse encontrar aí uma motivação simplesmente porque ele tem muito tempo (a perder?).

As coisas não são tão simples.

Evidentemente, é impossível apresentar um quadro, mesmo geral, da educação na prisão no mundo, porque, simplesmente as prisões são diferentes em cada cidade, em cada país, em cada continente, nas democracias, nos regimes autoritários ou ainda nos países em que a autoridade do Estado praticamente não existe mais. Nem mesmo o di- 
namismo democrático das sociedades serve de pista para se entre-aperceber a realidade educativa das prisões porque a Europa, em matéria de gestão prisional, não tem muitas aulas a dar. Por outro lado, também não tem muitas aulas a receber.

Se um quadro síntese não pode ser proposto, é possível, no entanto, oferecer alguns traços característicos dos ocupantes das prisões. Eles são pouco mais de dez milhões no mundo; seis milhões se encontram, mais ou menos igualmente distribuídos na Rússia, na China e nos Estados Unidos. Podemos evidenciar um descompasso entre a realidade democrática de um país e o nível de preocupação política relativa às prisões.

A maior parte dos detentos é constituída por pobres, tem um nível educacional muito baixo, jamais conheceram a escola ou, quando conheceram, sua experiência frequentemente terminou em fracasso; muitos detentos são jovens ainda e, em numerosos países, os migrantes (econômicos) constituem uma parte importante da população carcerária.

Face a esta situação, não apresentada, mas verificável em todos os países, o reflexo (cidadão e político) será fornecer cursos, ensino, formação profissional ou alfabetização, para que a delinquência não se repita.

Destacamos aqui uma das principais contradições da organização da educação na prisão: a iniciativa não é seguida de uma demanda dos principais interessados, mas da estrutura do próprio aprisionamento. Raramente vimos detentos pedirem massivamente a organização de cursos; muito raramente vimos uma prisão em rebelião porque os detentos denunciavam a falta de organização, o conteúdo ou a qualidade da educação organizada ali.

A única reivindicação dos detentos é sair e não de terem sua estada na prisão menos dolorosa ou mais interessante possível.

Como, nessas condições, apresentar o potencial da educação; garantir que os educadores não sejam confundidos com o conjunto de interventores do sistema carcerário; garantir que os guardas aceitem a valorização do espaço tempo da educação; apresentar aos detentos uma educação para toda a vida como algo diferente do risco de um novo fracasso escolar?

Precisamente porque são muito identificados com a repressão e a punição, programas de educação são frequentemente rejeitados, assim como outras iniciativas na prisão.

A educação nunca será a pitada de açúcar que permitirá engolir mais facilmente uma porção amarga - a prisão.

Enredada na contradição de punir e oferecer uma perspectiva às pessoas que não escolheram estar ali e que, para uma parcela dentre eles, já preparam sua saída e suas próximas vitórias ou vinganças, a educação na prisão raramente é acolhida como uma oportunidade.

Educação \& Realidade, Porto Alegre, v. 38, n. 1, p. 33-49, jan./mar. 2013.

Disponível em: <http://www.ufrgs.br/edu_realidade> 
A Educação na Prisão não é uma Mera Atividade

De qualquer forma, ela nunca é acessível a todos os detentos. Eu visitei as prisões de aproximadamente 80 países no mundo, quase todas eram superlotadas e, muito frequentemente, no final da visita, eu via algumas classes, não raras vezes, pobremente equipadas, que podiam acolher apenas algumas dezenas de estudantes. E as outras centenas? Desmotivados? Ignorantes? Desistentes? Indesejáveis? Muito numerosos? Sem dúvida, por tudo isso e muito mais, ausentes.

A problemática da oferta e da procura em educação dos jovens e adultos no cárcere é complexa. Há alguns anos, verificamos que, em geral, a maioria dos jovens e adultos que buscavam se inserir em algum programa educacional ou educativo no cárcere eram aqueles que já tinham um nível de educação elevado - por vezes muito elevado. Para outros, apesar das oportunidades, os que se situavam mais distante, ficavam afastados delas.

Isso significa que a educação é também um processo cultural que se autoalimenta. Quanto mais nos interessamos pelas coisas, mais estudamos, seja para a vida profissional ou para o simples prazer. Para alguns, a educação permanente é realmente um prazer. Só aceitamos nos inscrever em novos processos de aprendizagem porque os precedentes foram bem sucedidos, trouxeram o que procurávamos. Ninguém cultiva a nostalgia pelo fracasso. É também o caso na prisão.

Propor-lhes-emos, posteriormente, algumas reflexões que deveriam ajudar a operar uma distinção fundamental entre a educação na prisão e os outros serviços prisionais. É um ponto essencial para ser realmente aceito, como educador, em um quadro antieducativo como a prisão. Tomaremos agora apenas dois exemplos que ilustram a ambiguidade da participação nos cursos.

\section{A Cultura da Imitação}

A prisão solicita e impõe atitudes, condicionamentos, comportamentos. O bom detento não é aquele que tomará iniciativas, mas aquele que se conformará, obedecerá à sua condição de detento: faltivo punido. É necessário conformar-se aos códigos explícitos ou implícitos e certamente aos mais visíveis. De sua adaptabilidade ou submissão dependerá sua avaliação, sua ficha criminal e, portanto, seu futuro (judiciário). Se ele não é obrigado a se mostrar um detento feliz - não é para tanto, ele deverá, apesar de tudo, fazer como se tivesse compreendido a gravidade de sua falta, como se aceitasse a pena, fazer como se fosse mesmo normal viver em tais condições, fingir estar justamente interessado pelo que lhe apresentamos: esporte livre, religião, educação, canto, trabalho mal remunerado, tarefas etc.

Agir assim permitirá ser caracterizado como bom detento para o qual se considerará eventualmente uma diminuição de pena, uma saída penitenciária. 
Essa cultura de conformidade, adotada pelo detento, é a única chance para que ele possa sair melhor e mais rápido. Não é de se espantar que as atividades serão aceitas e que se participará delas. Seria utópico interpretá-las como motivação educativa. Há simplesmente pontos a ganhar para uma saída mais rápida. É assim que vimos os detentos que possuíam o nível de educação de base se inscreverem em cursos de alfabetização, porque ainda havia lugar e porque as horas e dias passados em classe eram considerados na concessão de eventuais remição ou na avaliação do comportamento. É suficiente, nessa cultura da imitação, se inscrever, estar, então, fisicamente presente.

Os educadores sabem, mas a contabilidade do aparelho penitenciário não é a da educação. Assim como o educador não deve saber o motivo do encarceramento do educando, ele não deve também tornar públicas as aquisições educativas do detento. Seria efetivamente intolerável que leves progressos, medíocres ou insignificantes em uma aprendizagem, influenciassem negativamente o dossiê penal do detento. $\mathrm{O}$ que se passa durante as atividades educativas diz respeito apenas ao educando e seu educador. A sacralização do espaço - tempo da educação prisional é uma condição fundamental para o exercício desta última.

\section{O Trabalho e a Formação Profissional}

É uma outra e bela ideia propor aos detentos um trabalho e/ou uma formação profissional. A maioria dos detentos, pouco qualificados, jamais trabalhou regularmente.

Trabalho e formação profissional são atividades raras na prisão e que nem sempre são bem distintas. Muito frequentemente, em nome da formação profissional, empregam-se os detentos por um salário pífio em um trabalho repetitivo que não comporta nenhuma dimensão de formação profissional, mesmo informal.

Raramente há aprendizagem pelo trabalho. Há subcontratação com único benefício das empresas privadas. O resultado disso é que o detento continuará a ver o trabalho como algo sistematicamente doloroso, pouco valorizado e verá, na organização geral, apenas uma injustiça a mais.

A organização do trabalho não concorre para valorizar as aprendizagens: os momentos do dia consagrados à educação são frequentemente os mesmos que os do trabalho, com a única diferença de que, mesmo mal pagos, estes últimos permitem algum tipo de benefício intramuros, além de poder enviar dinheiro à família.

No que concerne à educação, é possível se observar as mesmas coisas que já explicitadas com relação à formação profissional: nas prisões superlotadas, não há lugar para instalar oficinas de formação para 500, 1.000 e, por vezes, 2.000 detentos. A prisão seria transformada em

Educação \& Realidade, Porto Alegre, v. 38, n. 1, p. 33-49, jan./mar. 2013. 
uma vasta usina, assim como em uma escola se oferecesse realmente educação formal a todos.

Isso fica mais evidente quando examinamos as restrições de segurança: se já é difícil entrar na prisão com um canivete, imagina se distribuir martelos, machados, brocas, toda uma série de ferramentas que podem ser transformadas em armas para centenas de detentos reunidos nas oficinas de formação profissional? Se é difícil a gestão de tais ferramentas no interior do sistema penitenciário, impossível, portanto, também será a formação profissional generalizada.

Nas prisões, não há nem escola, nem oficinas profissionais para todos os encarcerados. Evidencia-se, em geral, apenas em algumas unidades e não em toda a parte, umas e outras para alguns. Significa que não podemos fazer nada?

\section{Do Detido ao Educando pelo Reconhecimento do Adquirido}

Repetimos frequentemente: a maioria dos presos é pobre, não só pobre em nível econômico, mas igualmente em termos de conhecimento escolar.

No entanto, esta realidade não deve fazer esquecer uma outra que está por vezes ligada a ela: estes pobres têm, de diversas formas, aprendido a sobreviver em condições difíceis. Um certo número de estratégias empregadas para sobreviver os levaram à prisão. Mais ou menos bem, mais ou menos honestamente, mais ou menos frequentemente, numerosos detentos são pessoas que tiveram de aprender a viver em lares desunidos e violentos, a viver longe de seus pais, na pobreza ou na miséria, desde a mais tenra idade, para se inventar um estatuto social, para sobreviver em gangues e grupos pouco recomendáveis que lhes prometiam uma solução rápida e feliz para seus problemas. Os detentos desenvolveram igualmente habilidades de dissimulação, organização de grupos e gangues, operações de vigilância e outras técnicas de roubo, de extorsão. Algumas vezes, eles conhecem bem o conjunto de redes de ajuda e solidariedade assim como fragmentos de legislação que estão a seu favor.

É preciso tomar nota desses adquiridos e trabalhar a partir deles, pois, a educação nunca parte do nada. É falso e ilusório pensar que a prisão será um novo ponto de partida, um novo nascimento a partir do qual uma nova educação será dada a um novo ser.

Na prisão, como alhures, aprende-se por necessidade. Aprendese, pois há urgência.

Necessidade e urgência de sobreviver no universo carcerário; de conhecer as redes de influência; de integrar as atitudes que serão positivamente consideradas para uma saída mais rápida; de saber como melhorar seu cotidiano; de guardar um mínimo de intimidade; de imi- 
tar contrição, necessidade e urgência de simplesmente existir. Nessas condições aprende-se rápido e se vai ao essencial.

A educação nunca parte do nada e negar isso é um dos grandes perigos quando se é educador em espaço de privação de liberdade. A educação que será organizada e proposta ali será apenas uma etapa no processo da vida de cada um em que aprendizados positivos e negativos se encadeiam entre si.

A especificidade da educação em espaços prisionais será sem dúvida ajudar o detento a identificar e hierarquizar as aprendizagens para lhes dar um sentido: para que elas possam lhe oferecer possibilidades de escolha com conhecimento de causa; para que a faculdade de escolher reencontre seu campo de ação, a saber o eu-aprisionado mas aprisionado por um certo tempo apenas.

Não se trata, então, para o educador, de começar por emitir um julgamento sobre os adquiridos do detento - o juiz colocado à frente do educador emitiu seu veredito. Está na ordem das coisas. O educador não tem que repetir, amplificar, relativizar ou mesmo comentar o julgamento da justiça.

O detento não chega do nada na prisão e nos cursos. Ele possui uma experiência compartilhada com outros detentos com os quais tem um universo de exclusão comum.

O educador parte da situação em que se encontra o educando, não de onde ele imagina que ele esteja. A educação em espaços de privação de liberdade, dirige-se a pessoas, não a detentos.

O objetivo não será, então, suscitar um pedido de perdão, a admissão de um remorso e a manifestação de tristeza. Na educação implementada nas prisões, começa-se bem frequentemente com estudantes enfurecidos, eventualmente revoltados e certamente cultivando um sentimento de injustiça e de incompreensão.

É, então, inicialmente isso a educação para jovens e adultos em situação de privação de liberdade: as trocas entre detentos relativas a suas experiências e aprendizagens diversas. Essa educação entre pares é geralmente utilizada em todas as prisões do mundo.

A questão essencial é então política: diante desta questão, o Estado de direito vai simplesmente registrar esta realidade (sobre a qual ele não tem nenhum controle) ou vai, também, organizar sua própria educação, com seus valores, seus professores e educadores, seus objetivos sociais, políticos e éticos?

A resposta é bastante evidente e os textos fundamentais dos Direitos Humanos lembram que o Estado é responsável pela educação para todos e em todo lugar.

O problema não será então saber se se organiza ou não a educação na prisão, mas qual educação será organizada ali. Se a autoridade pública não investe massivamente na educação, formal e informal na

Educação \& Realidade, Porto Alegre, v. 38, n. 1, p. 33-49, jan./mar. 2013.

Disponível em: <http://www.ufrgs.br/edu_realidade> 
A Educação na Prisão não é uma Mera Atividade

prisão, ela deixa de fato todo o espaço livre para as gangues, redes que gerem esta educação entre pares. Veremos mais adiante por que o Estado, como fiador dos assuntos públicos, não deve, de forma alguma, privatizar a educação em espaços de privação de liberdade.

\section{Educar na Prisão: um contrato entre educando e formador}

Diante das aprendizagens negativas, que apenas se consolidarão na prisão, o educador deve poder se identificar claramente, marcar seu território, sua especificidade e suas responsabilidades.

Lembremos que há, diante dele, um educando que não está feliz por estar ali, que sabe o que quer aprender, mas que a prisão certamente não lhe dará, que se encontra no jogo de sedução e de imitação: ele deve ser o bom educando apreciado por todos para poder sair mais rápido. $\mathrm{O}$ educador pode ajudá-lo em seu projeto?

Desde que tenha aceitado estar nesse confronto com o detento ${ }^{1}$, o educador deverá estar tranquilo não apenas quanto ao seu estatuto ele não faz parte dos avaliadores, controladores e guardas que cercam o detento cotidianamente - mas igualmente quanto à finalidade do processo empregado.

O contrato deve ser claro:

O educador

- não está ali para fazer mais rápido, mais barato e com mais eficácia o que os atores da educação (família, escolas, organizações de jovens, esportivas...) não fizeram pelo detento durante 20, 30 anos;

- não está ali para representar ou justificar o poder judiciário uma vez pronunciado o julgamento penal, o educador vai trabalhar com uma pessoa (detida, certamente, mas que será considerada como uma pessoa). O educador não tem que conhecer o motivo do aprisionamento;

- deve reivindicar sua especificidade em termos de estatuto, de abordagem e de conteúdo. Deverá se assegurará de que seu local só é acessível aos educandos. Os guardas não estão presentes (no máximo do lado de fora, se as medidas de segurança o exigirem);

- deve trabalhar em sinergia: trabalhando no nível da educação permanente, cooperará com programas de educação em saúde, na resolução de conflitos, com a educação parental, etc.;

- deve poder garantir que as falas dos detentos, assim como suas "performances educativas" fiquem no interior do grupo e não constituam, de uma maneira ou de outra, o dossiê penal.

De sua parte, o interno vai se inscrever em um processo que lhe ensinará a debater sem violência; a ouvir o outro sem interferir a todo 
momento; a definir um projeto com estes outros não escolhidos; fixar meios de conseguir isso e gozar um eventual sucesso, em parceria com todos os outros protagonistas. Isso levará tempo, haverá desencorajamento, agressividade. O educador deve saber de tudo isso.

Enfim, a prisão, como instituição, deverá reconhecer o trabalho de educação como um processo que envolve diferentes atores. A educação na prisão é também a educação (em sentido largo) pelo e para o conjunto do pessoal: administração, guardas, profissionais da saúde, pessoal de serviço, etc. Toda atividade, mesmo banal que possa parecer, pode ser oportunidade de educação não formal (refeição, higiene, relações sociais, lazer, etc.).

Será necessário garantir também que, na medida do possível, a transferência do detento para uma outra prisão seja evitada quando ele está efetivamente empenhado em um trabalho sobre si e com os outros.

\section{Aprender, Desaprender}

\section{O que se aprende na prisão:}

O que se aprende na prisão não são programas detalhados, módulos estruturados ou currículos pensados por peritos em educação. Aprende-se ali o que ali se encontra, como já mencionado, o que ali se compartilha com os outros.

A prisão é também um lugar em que se vai desaprender. O detento vai viver em uma instituição em que não deverá tomar nenhuma decisão, em que se pede para, sobretudo, não tomar alguma.

Assim,

- as refeições são fornecidas; eles não precisam fazer compras, gerir o dinheiro, preparar, nem lavar a louça;

- aprende-se a obedecer sem muito questionar o porquê e não se toma nenhuma iniciativa que possa bagunçar o ambiente. Após ter sido um mau cidadão, vai-se tornar um bom prisioneiro;

- vive-se sem dinheiro, sem pensar na moradia e em sua manutenção. O horário é repetitivo, os dias são iguais;

- aprende-se a trabalhar por um salário que não é um;

- aprende-se a perder sua intimidade, a viver em um mundo não misto, sem relações afetivas - ou muito pouco afetiva;

- aprende-se a repetir.

\section{O que se desaprende na prisão:}

Desaprende-se, então, toda tomada de iniciativa e não é a menor das contradições constatar que no dia da sua liberdade, espera-se que o

Educação \& Realidade, Porto Alegre, v. 38, n. 1, p. 33-49, jan./mar. 2013. 
A Educação na Prisão não é uma Mera Atividade

detento tome todas as iniciativas que lhe pediram para esquecer durante sua estada no cárcere. Do dia para a noite, ele deverá gerir seu dinheiro, seu lugar na hierarquia do trabalho, que talvez tenham encontrado para ele, suas relações sociais e afetivas.

Tudo isso é a educação da prisão, não a educação na prisão!

É neste contexto que começa o trabalho dos educadores.

\section{Educar na Prisão é Ajudar a Colocar em Perspectiva essas Aprendizagens, Reconhecê-las, Hierarquizá-las para Tirar Proveito de Algumas}

Educar é dar dignidade - ou mais exatamente - permitir a cada um reencontrar em si sua dignidade fundamental. Isso exige um trabalho de auto-avaliação: é preciso assumir que se está condenado e encarcerado, mas também se lembrar de como era antes e de como vai ser dentro em breve considerando que se trata ainda da mesma pessoa. Saber que haverá outros papéis a desempenhar que ainda não estão escritos.

Trabalhar com todos esses adquiridos é essencial na prisão. Não se parte nunca do nada e, sobretudo, não se quer partir de um ponto zero. Há experiências que podem ser compartilhadas e incluídas em um quadro bem organizado e essa é a razão pela qual a educação informal é tão importante na prisão.

Assim, é a experiência do grupo: mesmo se o grupo não se escolheu e se encontra em um lugar que ele próprio não escolheu, a experiência de viver em um grupo pode levar à compreensão de que as diferenças não são sistemática e inevitavelmente obstáculos. As prisões são lugares multiculturais e nesse espaço, aprender, compreender e aceitar as diferenças será certamente muito útil. Não é necessário muito material pedagógico para isso, mas certamente um pessoal penitenciário bem formado nesta dimensão e igualmente convencido de que a multiculturalidade pode ser enriquecedora.

Assim é a experiência cultural na prisão. Ao lado das redes informais de tráfico de toda espécie, há também o material cultural que circula: programas de televisão dos mais estúpidos, aqueles que fazem sonhar, aqueles em que se veem alguns se tornarem ricos e célebres rapidamente, programas de violência, revistas pornográficas, pôsteres de mulheres nuas, etc. toda essa cultura para pessoas que se encontram na prisão justamente porque sonharam, quiseram ser ricos e célebres, foram violentos como na TV, quiseram, à todo custo, possuir uma mulher como aquela do pôster. Não há, nessa contradição, um material de primeira mão para uma educação cívico-cultural?

Não se trata de ajudar a passar o tempo ou fornecer uma educação pobre às pessoas pobres, mas de propor um quadro da expressão do 
mal-estar, da incompreensão, dos sentimentos mitigados, misturados, contraditórios. Dar dignidade é dar confiança.

Não se educa alguém porque se despreza. No limite, condicionase (provisoriamente).

Mas então, por que e como reconhecer alguns aprendizados?

Como, em uma situação de fracasso, retraçar seu percurso? Como reconhecer, para si, o fracasso? Reconhecer não quer dizer valorizar, por que consagrar tempo em reconhecer o que se percebe como fracasso? Por que reconhecer novamente o que foi nomeado pelos outros como "fracasso"? Por que lembrar acontecimentos que não se religam entre si e aparecem mais do domínio do acaso que da necessidade? Por que não esquecer tudo e abrir uma página em branco do caderno da vida, pois, só se pode valorizar o que se gosta em si? E Aquilo de que se orgulha?

No entanto, é daí que se parte: reconhecer-se e deixar de ser apenas um detento; reconhecer-se como educando. Só será possível reconhecer-se em suas experiências se, durante um tempo, houver outro papel a ser desempenhado que não o de detento.

Sem negar o presente, só é possível começar um trabalho de educação se se lembrar de que se é também e ainda, apesar das circunstâncias, um filho ou uma filha, um pai ou uma mãe, alguém que tem valor aos olhos de alguém, um cidadão.

O processo educativo tem início quando o detento torna-se (provisoriamente) um educando e este educando encontra sua identidade social e afetiva profunda. Com esse estatuto de educando, reconhecido por si e pelos outros, ele poderá desenvolver os projetos para si e para os outros.

É por isso que a prisão é antieducativa. É porque ela fixa um indivíduo em seu papel, um papel que é socialmente útil - apenas para a opinião pública -, mas que não contribui em nada com uma educação permanente para o faltivo.

\section{O educador na prisão vai, então, contra a corrente}

A passagem pela prisão por vezes define ou reforça uma identidade. Assim, percebe-se que alguns valentões - um pequeno grupo, portanto, - se vangloriam de sua passagem pela prisão; não se trata de um tipo de consagração de uma vida de grande delinquência que deve imperativamente passar por certas caixas como a prisão. Mas, na grande maioria, Monopólio da vida, acontece também de alguns delinquentes, não muito perigosos, jogarem o jogo e descobrirem no espaço prisional uma consagração que eles não haviam tido fora dele, inclusive no seio do próprio grupo. A prisão vai lhe ensinar a exercer um poder.

Esses casos não são maioria. Muitos detentos procuram, antes de tudo, esquecer e fazer esquecer sua estada na prisão. Em contrapartida, os aprendizados informais ficam.

Educação \& Realidade, Porto Alegre, v. 38, n. 1, p. 33-49, jan./mar. 2013. 
A Educação na Prisão não é uma Mera Atividade

É necessário, então, que a prisão ensine algo de diferente da própria prisão!

Esta insistência em ver o detento apenas como detento - visão constante durante o encarceramento e ainda nos anos seguintes - impede o trabalho de outros aspectos da personalidade.

Não se trata de negar o passado e o crime, não se trata de dar um certificado de boa reputação àquele que não merece. Trata-se de ajudálo a enxergar que é possível fazer outras coisas, que ele é capaz de outras atitudes, outros projetos, outras afeições. É preciso simplesmente lembrar-se de que vários detentos jamais tiveram oportunidade de experimentar isso, vindo não raras vezes, como dissemos, de meios pobres e pouco estruturados.

Mencionemos aqui que, justamente para salvar essa dinâmica, é impensável que a educação prisional seja privatizada na medida em que ela não é avaliável em números. A educação privatizada e estandardizada não acompanha cada um na reapropriação de sua história, pois ela supõe um modelo educativo standarte receitas de aplicação que não levam muito em consideração as histórias individuais. Preencher os espaços do questionário de avaliação não é educação. Compreender os espaços de sua vida, na companhia de outros em um contexto educativo, é um processo de educação permanente e é por isso que falamos em educação para toda a vida.

\section{Nem Todo Mundo Pode ser Educador na Prisão}

\section{Sempre houve educadores na prisão}

Não vamos fazer aqui a história da educação na prisão. Vamos simplesmente constatar que houve, ao lado da prisão repressiva, pelo menos uma autoridade moral que estendia a mão, que queria compreender, por vezes perdoar, dar uma segunda chance, dar uma esperança; isso se deu frequentemente no caso de comunidades religiosas que, mesmo se não reivindicassem um projeto educacional como tal, manifestavam, de alguma maneira, a vontade de oferecer novas perspectivas ao delinquente em via de normalização - e isso em nome de valores supremos. Seria necessário recolocar o pecador no bom caminho.

Essas comunidades religiosas não desapareceram, pelo contrário, em certos países, elas proliferam da mesma forma na prisão. É verdade que o pecado original, a redenção e o perdão - noções chave das igrejas e seitas - encontrão sempre excelente acolhida na prisão, ao menos da parte dos responsáveis.

Dentro e em torno das prisões sempre houve indivíduos e instituições que, querendo ultrapassar a realidade da delinquência e da punição, que eles próprios não contestavam, se deram por missão abrir novas pistas como se, em si e desde sempre, a instituição carcerária e o sistema judiciário fossem definitivamente incapazes de fazer isso. 
Os educadores de hoje se tornaram os novos missionários ou, como Sísifo, são essa massa compósita e frequentemente pouco reconhecida, condenada a retomar sem cessar o mesmo caminho da militância para abrir uma via diferente aos detentos?

Esses grupos de educadores são de duas categorias: uma vem da sociedade civil e é formada por militantes para quem a educação e a dignidade humana se confundem com seu trabalho em favor dos direitos humanos; o outro vem das instâncias públicas, dos ministérios da educação, dos assuntos sociais e culturais.

Às vezes estas duas categorias coabitam no interior de uma mesma prisão. Isso é bom porque é importante que a sociedade civil esteja presente na prisão (via ONGs educacionais) assim como é preciso que o Estado assuma suas responsabilidades - eles estão por vezes em concorrência com as igrejas e seitas.

O Estado, como poder público, deve organizar esta educação gratuita para todos ainda que, por razões de filosofia política ou de recursos, delegue uma parte dessa tarefa a organizações reconhecidas pela sociedade civil. A delegação desta responsabilidade deve, evidentemente, ser acompanhada por montantes financeiros e pela legitimidade necessários ao bom cumprimento desta tarefa.

\section{Bibliotecas}

Tomaremos o exemplo das bibliotecas para mostrar que no interior de um sistema congelado como a prisão podemos reinventar alguns serviços, inscrevê-los na perspectiva da educação permanente.

A biblioteca é frequentemente um cômodo fechado. Quantas vezes, eu quis visitar a biblioteca e, espantados, nos perguntamos onde estava a chave.

A biblioteca é um dos lugares fechados no interior de uma construção (prisão) igualmente bem fechada. Os livros são bem protegidos.

Mas de quem, do que? Dos detentos que, em sua grande maioria, nunca colocaram os pés em uma biblioteca e que, quando ali entram, raramente encontram livros que os interessam?

Se a imagem da cultura fechada na prisão é, sem dúvida, de fácil construção, ela corresponde ainda assim a uma certa realidade, pois a cultura na prisão é a cultura da prisão.

A cultura da prisão é a educação por pares, é a reprodução dos comportamentos ou a imitação dos comportamentos valorizados. É a cultura do mais forte, da desenvoltura, do silêncio, do transitório.

Aprender, será passar a uma outra cultura, a do exterior, aquela na qual ainda não se chegou.

Nessas condições, a educação informal não será bem compreendida imediatamente, pois, para os detentos, a educação é o ensino: um 
banco, um caderno, um lápis e um professor que sabe. Então, quando lhe propomos um teatro, uma foto, ou toda uma outra forma de expressão, uma vez passado o primeiro reflexo machista - "isso é coisa de mulherzinha" -, um novo medo se instala, um grande vazio aparece: "Não tenho nada a dizer”, "o que eu penso, eu guardo para mim”; “o que eu penso não tem importância”.

Subentendido: com o meu passado, o que eu posso apresentar aos outros que me valorize; o que eu posso encontrar de positivo que justifique ir adiante? Pois, em educação, seguimos sempre avante, não (re) partimos nunca do zero, acrescentamos aprendizagens a outras aprendizagens.

É um dos perigos da educação em espaços de privação de liberdade: esquecemos a má vida, esquecemos momentaneamente a travessura; tentamos esquecer inclusive o estatuto de detento.

Quantas vezes não ouvimos "é um novo começo, dessa vez é a coisa certa”.

A educação é um processo. Não educamos um detento para prepará-lo para sair. Para isso, o informamos ou guiamos. Damos-lhe as balizas. A educação na prisão ou alhures, é outra coisa.

É por isso que conceber e animar mais e de outra forma as bibliotecas constitui uma questão forte do universo penitenciário.

Se há, paradoxalmente, pouco interesse para o próprio livro, o interesse existe pela leitura quando ela coincide com a procura por informações úteis e diretas.

Não se trata de mero jogo de palavras, pois, se aceitamos isso, temos uma definição precisa do que deveria ser a biblioteca na prisão algo que não se reduz a um lugar em que há livros a serem distribuídos.

Muito frequentemente os livros ali agrupados não têm ligação alguma com as atividades educativas da prisão, eles são muito técnicos ou muito especializados ou ainda impróprios para adultos, não têm interesse algum. São frequentemente os não vendidos de segunda mão das lojas ou donativos que ocupam espaço nas bibliotecas públicas.

Como não prever, para as sessões de educação, que uma sala de 10, 20 às vezes 50 lugares em uma prisão de 500 ou 1.000 pessoas não é, de forma alguma, um incentivo, ainda mais quando sabemos que não há muitos outros lugares para a leitura na prisão: a superlotação da cela, o ambiente geral e a TV do codetento não tornam fácil o tipo de leitura defendida.

O bibliotecário não termina seu trabalho quando os livros são distribuídos. Para alguns detentos, o livro será um objeto simbólico; para outros, é preciso prever um modo de emprego discreto.

É preciso acompanhar a leitura, mas sobretudo o leitor em suas hesitações, seu medo de não entender o essencial do texto, de ser ridículo ou vergonhoso mostrar seu analfabetismo, sua vontade de começar 
uma atividade que não é "de seu feitio", de aparecer como um traidor do seu meio, de sua cultura, dos seus códigos, da sua maneira tradicional de aprender, de ter em mãos um livro cujo título pode quebrar sua imagem.

Este acompanhamento é a essência mesma do trabalho do bibliotecário na prisão. Este deve ser um elemento essencial de sua formação. As bibliotecas devem se tornar lugares de cultura, lugares de produção de cultura.

Os lugares, ou seja, os vários espaços para informar, fazer conhecer, interrogar, intrigar .Esses lugares não devem ser apenas os próprios locais, mas igualmente os muros em que informações e cartazes podem ser apresentados, os salões, o tribunal, etc.

As bibliotecas podem ser também lugares de criação de cultura. Existem experiências de fabricação de jornal, de emissões de rádio e TV, de organização de exposição de desenhos, de grafites, etc.

A biblioteca não é apenas um lugar de consumo e apropriação simbólica de uma cultura estrangeira, ela pode ser um dos lugares de criação e de expressão do universo atual de cada um.

Os interventores da saúde, da ação social, as equipes da cozinha, de formação profissional, os agentes penitenciários, as famílias devem fazer com que a prisão se torne um lugar em que se aprenda a colocar questões sobre si, os outros e a sociedade e não apenas um lugar em que se aprende respostas simplistas para realidades complexas.

Aprender a colocar essas questões e desenvolver estratégias para procurar respostas cujos elementos de algumas estão nos livros, folhetos, revistas, no rádio, na TV, nas animações que chegam do exterior, é o trabalho do bibliotecário. É esse o trabalho dos criadores e difusores de cultura.

Ler não é a atividade de um ser passivo, de alguém que quer passar o tempo. Ler é uma relação dinâmica com o texto, com a imagem, com o filme, com as questões, com a história.

Multipliquemos os lugares de informações, multipliquemos as categorias de informação, diversifiquemos os suportes da informação (imagens, música, expressão corporal, desenhos, grafites, o escrito, etc.) para que a biblioteca seja realmente integrada à prisão e possa modestamente contribuir com a capacidade reflexiva do detento, com seu conhecimento de causa, com um outro futuro quando da saída do estabelecimento.

\section{Educar na Prisão é Reconciliar com o Ato de Aprender}

Aprender ao longo da vida é deixar momentaneamente seu estatuto provisório de detento para se inscrever em uma perspectiva mais a longo prazo sem acrescentar um julgamento social ao julgamento penal.

Educação \& Realidade, Porto Alegre, v. 38, n. 1, p. 33-49, jan./mar. 2013. 
A Educação na Prisão não é uma Mera Atividade

Apenas quando for permitido ao detento não ser apenas um detento - mesmo se ele ainda vá passar por vários anos de prisão - poderemos introduzir programas mais "clássicos" de educação como a alfabetização, cursos de língua (inclusive de língua materna), história, geografia, elementos de psicologia parental, da compatibilidade, etc. ou de formação profissional com a condição de ser organizada, pelos motivos que apresentamos, em coordenação com escolas profissionais, geograficamente próximas da prisão.

Esta reconciliação com o ato de aprender, às vezes até com a alegria de aprender, é o objetivo último que a prisão pode ter.

Não há escola na prisão, a educação na prisão não poderá fazer mais. Não está claro que seja sensato - considerando os meios existentes - construir escolas no interior das prisões, mas esse é um outro debate.

\section{À Guisa de Conclusão}

Esse sobrevoo sobre as questões e contradições da educação na prisão deve nos incitar à (re)colocar a questão das prioridades socioeducativas de uma sociedade em relação à gestão dos fundos públicos: por que a educação na prisão se torna uma preocupação urgente enquanto a educação dos (futuros) detentos o era em menor grau? Antes do seu encarceramento, o detento, como muitos outros excluídos, não teve todas as possibilidades ou o apoio necessário para aprender. O conjunto do sistema educativo não chega a diminuir (e apagar) a diferença social.

Por que a educação do detento se torna uma questão importante enquanto no exterior isso era menos urgente?

É paradoxal constatar que operamos cortes importantes nos orçamentos sociais, de saúde e de educação para esperar um equilíbrio orçamentário que será prejudicado pela implementação de uma política penal, sempre mais onerosa, com a finalidade de cuidar dos delinquentes cada vez mais numerosos e que custam cada vez mais caros - se nos ativermos apenas ao critério econômico -, sem grande resultado.

No entanto, conhecemos os números: a prevenção custa mais barato que a repressão; no entanto, em nome da boa gestão, fazemos o contrário. Fazemos más escolhas economias e, sobretudo, más escolhas sociais.

Então, a educação na prisão seria um luxo para os países ricos, um consolo para aqueles que acreditam na bondade do homem, uma cobertura humanitária para esconder o impasse no qual se encontram todas as prisões do mundo?

Os detentos não são meus amigos, mas não é necessário ser meu amigo para que eu reconheça a cada um seus direitos. O direito não é dado por compaixão, mas porque é um direito. Ele não necessita de ex- 
plicação alguma. É porque decidimos viver em sociedade, reconhecendo a cada um os mesmos direitos, que esta exigência moral se torna uma exigência social, jurídica.

Não se trata de bem ou mal no reconhecimento dos direitos de cada um.

Recebido em 16 de julho de 2012 Aprovado em 18 de dezembro de 2012

\section{Nota}

1 Em vários países, educadores são enviados contra sua vontade para trabalhar na prisão.

Marc De Maeyer é consultor internacional em educação e assuntos sociais. Foi pesquisador principal (Senior Research Spécialist) na UNESCO onde implementou o programa de educação na prisão. Foi assessor científico do programa educação na prisão do projeto EUROSOCIAL. País: Bélgica.

E-mail:marcdemaeyermarc@gmail.com

Tradução: João Marcos Mateus Kogawa 